\title{
ROTINAS EVOLUCIONÁRIAS: IDENTIFICAÇÃO DE UM FRAMEWORK A PARTIR DO RESGATE DO INDIVIDUALISMO METODOLÓGICO, DO PATH DEPENDENCE E DA MEMÓRIA ORGANIZACIONAL
}

\author{
EVOLUTIONARY ROUTINES: IDENTIFICATION OF A FRAMEWORK BASED ON A REVIVAL OF \\ METHODOLOGICAL INDIVIDUALISM, PATH DEPENDENCE AND ORGANIZATIONAL MEMORY
}

RUTINAS EVOLUCIONARIAS: IDENTIFICACIÓN DE UN FRAMEWORK DESDE EL RESCATE DEL INDIVIDUALISMO METODOLÓGICO, DEL PATH DEPENDENCE Y DE LA MEMORIA ORGANIZACIONAL

OBERDAN TELES DA SILVA

Doutor

Professor na Universidade Estadual do Rio Grande do Sul - Brasil oberdanteles@hotmail.com

ORCID: http://orcid.org/0000-0003-1319-4839

CASSIANE CHAIS

Doutoranda

Universidade de Caxias do Sul - Brasil

cassichais@gmail.com

ORCID: http://orcid.org/0000-0002-1922-9273

ERIC CHARLES HENRI DORION

Doutor

Universidade de Caxias do Sul - Brasil echdorion@gmail.com

ORCID: http://orcid.org/0000-0002-3472-3835

PELAYO MUNHOZ OLEA

Doutor

Universidade de Caxias do Sul - Brasil

pelayo.olea@gmail.com

ORCID: http://orcid.org/0000-0003-2183-8112

Submetido em: 26/05/2018

Aprovado em: 03/10/2018

Doi: alcance.v25n2(Mai/Ago).p211-225

\section{RESUMO}

O objetivo deste ensaio teórico é a composição de um framework para o estudo das rotinas evolucionárias, decorrentes de inferência e relacionadas à memória organizacional, path dependence e individualismo metodológico. O framework adota a lógica do individualismo metodológico (1), individualismo metodológico interacionista (2), método analítico compositivo-genético causal (3) e microeconomia sistêmica (4). Na segunda inferência tem-se, além da aprendizagem, a possibilidade de atenuação do conceito de irreversibilidade do path dependence. Na inferência em prol da mudança, tem-se no individualismo metodológico interacionista (2), os agentes dotados de seus repertórios interagindo na seleção e retenção por meio de suas memórias transativas, proporcionando assim a ligação entre os repertórios individuais e a rotina, contribuindo com o sistema generativo do construto. Dentre os achados, este ensaio entende que as rotinas devem ser estudadas a partir de uma lógica de interação partindo do indivíduo para a organização, valorizando o potencial de variação humana e as propriedades emergentes geradas na evolução com o ambiente, sendo necessário o mapeamento do padrão ou

Revista Alcance - Eletrônica - vol. 25 - n. 2 - Mai./Ago. 2018 
da forma destas interações, pois a estrutura organizacional representa a absorção destes padrões. Como elementos limitantes do estudo, tem-se a necessidade de ampliar conceitos da gestão sistêmica e autoorganização no contexto da economia evolucionária. Contudo, estudos empíricos podem ser desenvolvidos tomando por base esse framework.

Palavras-chaves: Rotina. Economia Evolucionária. Path Dependence. Memória Organizacional.

\section{ABSTRACT}

The objective of this theoretical essay is the composition of a framework for the study of evolutionary routines, arising from inference related to organizational memory, path dependence and methodological individualism. The framework adopts the logic of methodological individualism (1), interactionist methodological individualism (2), causal compositional-genetic analytic method (3) and systemic microeconomics (4). In the second inference, besides the learning, we have the possibility of attenuation of the concept of irreversibility of the path dependence. In the inference for change, we have in interactionist methodological individualism (2) agents endowed with their repertoires interacting in selection and retention through their transitive memories, thus providing a link between the individual repertoires and the routine contributing to the system of the construct. Among the findings, this essay understands that routines should be studied from an interaction logic, moving from the individual to the organization valuing the potential of human variation and the emergent properties generated in the evolution with the environment. A mapping of the pattern or form of these interactions is also necessary, since the organizational structure represents the absorption of these patterns. One of the limitations of this study is the need to extend concepts of systemic management and self-organization in the context of evolutionary economics. However, empirical studies can be developed on the basis of this framework.

Keywords: Routine. Evolutionary economics. Path Dependence. Organizational Memory.

\section{RESUMEN}

El objetivo de este ensayo teórico es la composición de un marco para el estudio de las rutinas evolucionarias, derivadas de inferencia relacionadas a la memoria organizacional, path dependence e individualismo metodológico. El marco adopta la lógica individualista metodológica (1) interacionist individualista metodológica (2) método de análisis genético composicional-causal (3) y microeconomía sistémica (4). En la segunda inferencia se tiene además del aprendizaje la posibilidad de atenuación del concepto de irreversibilidad del path dependence. En la inferencia a favor del cambio, se tiene en el individualismo metodológico interaccionista (2) los agentes dotados de sus repertorios interactuando en la selección y retención por medio de sus memorias transitivas, proporcionando así la conexión entre los repertorios individuales y la rutina contribuyendo con el sistema generativo del constructo. Entre los hallazgos este ensayo entiende que las rutinas deben ser estudiadas a partir de una lógica de interacción partiendo del individuo a la organización valorizando el potencial de variación humana y las propiedades emergentes generadas en la evolución con el ambiente, siendo necesario el mapeo del patrón o forma de estas interacciones, pues la estructura organizacional representa la absorción de estos patrones. Como elementos limitantes del estudio se tiene la necesidad de ampliar conceptos de la gestión sistémica y autoorganización en el contexto de la economía evolutiva. Sin embargo, los estudios empíricos pueden desarrollarse tomando como base este marco.

Palabras claves: Rutina. Economía Evolucionaria. Path Dependence. Memoria Organizacional.

\section{INTRODUÇÃO}

As rotinas organizacionais foram estudadas especialmente pela teoria evolucionária de Nelson e Winter (2005). As rotinas, contudo, apresentam complexidade de compreensão, tendo em vista a ambiguidade conceitual. Existe uma carência de aprofundamento das rotinas na ciência social (Becker, 1982).

De acordo com Dönmez e Grote (2016), a ausência de variação torna a rotina estável e sem dinâmica, porém a complexidade se acentua quando inserida na dinamicidade e quando operacionalizadas por atores. Essa dinamicidade, contudo, conduz a desvios estratégicos gerando, sob efeito, a mudança e também a inovação. 
A inovação e a mudança, dessa forma, estão relacionadas não em estruturas de mercado estáticos legitimados pelos custos de transação, mas sim pelos princípios da teoria evolucionária que prevê aprendizagem em combinações de recursos e informações em uma situação de desequilíbrio cujas firmas apresentam assimetria de poder, estratégias e de coordenação. Portando, a dinamicidade da teoria evolucionária, caracterizada pelo movimento e mudanças constantes, encontra-se na diversidade das estruturas e de performances. A economia evolucionária difere da teoria ortodoxa que apresenta princípios do paradigma mecanicista reducionista (Hodgson, 1998). Essa heterogeneidade das firmas, legitimadas pela teoria evolucionária, é resultado do processo de aprendizagem acumulado pelas organizações ao longo de sua existência. Fato que remete ao conceito de path dependence.

A teoria evolucionária tem como fundamentação ainda as rotinas, que, por sua vez, apresentam conceitos antecedentes neo-schumpeterianos. Existe, dessa maneira, correlação entre a combinação de novas rotinas e a inovação organizacional. Além disso, existe correlação nos estudos neo-schumpeterianos entre rotinas organizacionais e performance a partir do contexto de path dependence (Loebel, 2012). Tendo relação com a inovação Schumpeteriana, as rotinas necessitam ser estudadas à luz da dinamicidade do mercado, contextualizando 0 caráter de mudança, adaptação e o potencial de aprendizagem que estas podem promover, tendo como princípio o repertório individual dos agentes (Nelson \& Winter, 2005; Evans, 2011).

O ensaio teórico apresenta como objetivo geral a identificação de um framework conceitual de rotinas evolucionárias a partir do individualismo metodológico, da memória organizacional e do path dependence. Para isso, realizou-se uma busca nas bases Web of Science e Scopus sob os termos "individualismo metodológico", "rotinas" e "memória organizacional". Utilizou-se a base Scopus por ser uma das mais revisadas por pares e a Web Science, que se destaca pela diversidade de áreas de pesquisa. Pesquisaram-se, dessa forma, os construtos pelo título, usando como refinamento o domínio, área específica e revisão bibliográfica, em que se utilizaram como fonte de pesquisa artigos com ênfase teórica por relevância, bem com a utilização dos artigos mais citados. Por ser um ensaio teórico, o capítulo do método não está relacionado no artigo. Para a construção deste trabalho, foram utilizados os sistemas de inferência de Foucault (2008), estabelecendo as relações simétricas entre os conceitos dos construtos rotina, memória organizacional, path dependence e individualismo metodológico. Tendo identificado as inferências em termos de similaridade a partir do agente e de interação entre os construtos, estrutura-se um framework a partir destas simetrias, estabelecendo uma coerência conceitual para estudo das rotinas na economia evolucionária. 0 framework desenvolve-se à luz de Vaisman (2006), admitindo o caráter de possibilidade de evolução teórica a partir destes construtos.

\section{REFERENCIAL TEÓRICO}

A seguir, apresentam-se conceitos referentes à teoria da economia evolucionária e à sua relação com rotinas, conceitos de memória organizacional, path dependence e individualismo metodológico. Tem-se a apresentação das inferências entre os construtos que, após, fundamentam a estruturação do framework.

\subsection{A Teoria da Economia Evolucionária}

A teoria econômica evolucionária, para Possas (2008), fundamenta-se na biologia evolucionária que se desenvolveu na década de 50 por meio de Alchian (1950), Friedman (1953) e Becker (1982). Por abarcar também elementos exógenos, 0 ambiente na teoria da economia evolucionária não é visto como um processo estático. Ademais, endogenamente, as organizações representam um conjunto de competências e habilidades que evoluem na interação com o ambiente competitivo. Por ser decorrente dos preceitos da biologia, a teoria econômica evolucionária diz respeito, portanto, a dois elementos: o sistema de seleção do ambiente, isto é, exógeno, do mercado e a capacidade de adaptação das organizações (Bataglia \& Meirelles, 2009). A adaptação, que é endógena, decorre da variação gerada pela necessidade de alinhamento da organização ao ambiente competitivo.

O processo de adaptação é desenvolvido pelas rotinas que evoluem ao longo da existência da organização. As rotinas, na teoria evolucionária neo-schumpeteriana, representam uma estrutura analítica que gera potencial de análise promovendo, sob efeito, nas organizações, diferenças de produtos, mercado, capacidade de mudança e de aprendizagem (Loebel, 2012). As rotinas, na teoria evolucionária, objetivam o lucro, contudo, não necessariamente obterão a maximização. Isso reflete a influência da teoria das organizações de Cyert e March (1992) na economia evolucionária. Nessa linha, o conceito endógeno, representando pelo papel das rotinas, não

Revista Alcance - Eletrônica - vol. 25 - n. 2 - Mai./Ago. 2018 
gera efeitos apenas à organização, mas ao ambiente competitivo. Ressalta-se que a teoria econômica evolucionária decorre das doutrinas de Karl Marx, dado que é a organização capitalista que endogenamente define o sistema econômico (Nelson \& Winter, 2005). Por tratar-se de uma teoria endógena, ela tem influência nas políticas governamentais dada a assimetria das organizações, extrapolando puramente 0 viés singular da organização apenas.

A teoria econômica evolucionária, por se tratar também de elementos endógenos, representa um subconjunto da teoria da firma, abrangendo visão baseada em recursos e capacidades (Hodgson, 1998). Assim como Adam Smith (1976) e Karl Marx (1974), a teoria evolucionária caracteriza a organização como um conjunto de competências resultantes da habilidade e do conhecimento tácito. Nesse sentido, a contribuição na teoria econômica evolucionária foi desenvolvida por Nelson e Winter (1982) por meio da analogia da biologia evolucionista, baseando seus trabalhos em economistas não ortodoxos que defendiam a impossibilidade da maximização e do equilíbrio econômico (Bataglia \& Meirelles, 2009). A teoria evolucionária de Nelson e Winter (2005) apresenta princípios da teoria neo-schmpeteriana (Possas, 2008). Ademais, a teoria evolucionária da economia é multidisciplinar, pois tem como fundamentos a teoria da inovação desenvolvida por Schumpeter, teoria dos sistemas, teoria do gerenciamento das organizações e teoria da evolução das espécies da biologia (Betlagia; Meirelles, 2009).

Nesse sentido, autores como Thorbjon Knudsen e Geoffrey Hodgson formataram uma meta teoria baseada no darwinismo generalizado para explicar as mudanças econômicas a partir dos elementos variação, seleção e retenção (Schumbert, 2014). Para esses autores, toda a ciência social deve focar seus estudos nas explanações causais do realismo sociocultural. Afirma que o darwinismo generalizado, referente ao processo evolucionário, é composto por múltiplos agentes heterogêneos em um sistema complexo de interação. Os princípios evolucionários são importantes para explicar como as organizações são formadas e como geram mudanças (Nelson, 2002). Para Nelson e Winter (2005), a economia está mais relacionada à biologia econômica do que à economia mecanicista, pois a primeira é mais complexa. A premissa da teoria evolucionária diz respeito às ações dos indivíduos e também à interação deles, sendo resultado do compartilhamento de pensamentos e ações.

Nesse sentido, a teoria evolucionária trata do comportamento, isto é, de padrões de ação que precisam ser compreendidos por meio da aprendizagem, em nível de indivíduo ou coletividade. Por meio da compreensão destes padrões de ações comportamentais, é possível caracterizar a assimetria do desempenho organizacional e os elementos geradores da competitividade inter e intra firmas. Assim, a teoria econômica evolucionária surge como forma de contrariar o estudo das firmas apenas pela lógica dos custos de transação, típica da teoria ortodoxa da economia, o que, sob efeito, nesta corrente gera cálculo de custos racionais a partir da redução da interação entre os indivíduos (Hodgson, 1998). Enquanto que a teoria econômica evolucionária trata a aprendizagem como um processo de reconstrução, a teoria ortodoxa da economia a relega à correlação estatística a partir da racionalidade. Assim, percebe-se que a teoria econômica evolucionária, diferentemente da ortodoxa, preza pelo desequilíbrio, admitindo evoluções decorrentes de um ambiente em estado de assimetria com períodos de evolução e involução, cujos múltiplos agentes interagem a partir de suas rotinas e de suas formas diversas de implementação de técnicas de produção, de capital e aprendizagem. Na economia ortodoxo, entretanto, tem-se a busca pelo equilíbrio por meio do calcula racional dos efeitos, tendo influência nos fisiocratas franceses que careciam de uma sociologia econômica mais estruturada (Schumpeter,1954). Na teoria econômica evolucionária, que tem como base o desequilíbrio estocástico, o processo de aprendizagem compreende a desestruturação do equilíbrio, gerando criatividade por meio do processo disruptivo.

A lógica da economia evolucionária segue os preceitos da perspectiva de Darwin, isto é, variação, seleção e retenção, apresentando potencial nas pesquisas relativas à gestão. Esse modelo evolucionário de Darwin, quando inserido no contexto social, abrange elementos imperfeitos de seleção de aprendizagem e descoberta. Assim, a teoria evolucionária difere da teoria econômica tradicional pela sua incapacidade de predizer 0 comportamento futuro da organização (Winter, 1964). Contudo, a teoria da economia evolucionária, quando combinada com as diretrizes da estratégia organizacional, promove à organização, dada suas múltiplas relações com diversos stakeholders, otimização de modelos de adaptação e de mudança (Evans, 2011).

A teoria evolucionária apresenta como pilares ontológicos a variação, a seleção e a retenção (Laakkonen \& Kansikas, 2011). A primeira compreende relacionamento com o cliente, alterações no sistema de produção, entre outros. A variação engloba a alteração das atividades que a organização desenvolve, com o intuito de acoplar a mudança ao ambiente (Bataglia \& Meirelles, 2009). Conforme os autores, a variação tem origem na imitação dos concorrentes por propagação seletiva, cuja organização duplica variações que surgem de forma emergente como 
forma às pressões institucionais e também por seleção racional, em que os agentes percebem potenciais de variação em benefício da organização. A variação compreende também os atores organizacionais, as atividades do sistema econômico como novos produtos, processos e produção. Compreendem, ainda, modificações formais e informais como incentivos, novos programas organizacionais, entre outros (Evans, 2011). Para ele, a variação pode ser:

a) cega: ocorre de forma aleatória ou não intencional, como por erro (Loebel, 2012).

b) intencional: é a busca da solução de restrições por meio de planejamento institucional prévio, objetivando incentivar o comportamento inovador (Loebel, 2012).

A seleção refere-se à escolha de elementos do ambiente, tendo como causa o processo de competição. É a eliminação de certas variações a partir de forças de mercado, normas institucionais e competição. Já a retenção compreende a adoção de certos processos ou política organizacional, gerando vantagem à organização e representando a reprodução de rotinas e processos (Evans, 2011).

\subsection{As rotinas e a teoria evolucionária}

As rotinas, a partir dos preceitos do Darwinismo Generalizado, representados pelos elementos de variação, seleção e retenção, carregam informações para soluções de determinados problemas adaptativos do ambiente, sendo responsáveis por reter, transferir ou copiar normas sociais, justificando por que determinadas organizações prosperam e tornam-se mais produtivas (Schumbert, 2014). Para Hodgson e Knudsen (2004), as rotinas são replicadoras que carregam informações que podem criar novas entidades e as organizações, por sua vez, como grupos sociais e instituições são interagentes.

$\mathrm{Na}$ teoria da economia evolucionária, as rotinas assemelham-se a genes. Apresentam estabilidade determinando o comportamento da organização, sendo suscetível, contudo, ao ambiente na qual a organização está inserida. Assim as rotinas são determinadas e selecionadas, apresentam hereditariedade, pois as rotinas de maior competitividade intraorganizacional espalham-se no mercado, além do que, diante de restrições no mercado, as organizações buscam novas rotinas (Vromem, 2006).

As rotinas também são caracterizadas por apresentarem inércia ou estabilidade endógena, sendo formadas por repetição (Pentland, Feldman, Becker, \& Liu, 2012). A estabilidade das rotinas diz respeito à ausência de variação. Paradoxalmente apresentam capacidade de mudança endógena, quando o ambiente se modifica. A mudança, contudo, tem como antecedente a flexibilidade que significa assumir riscos e aproveitar oportunidades. Apresentam ainda capacidade de absorção, gerando aprendizagem organizacional por meio de aquisição e transformação do conhecimento explorado (Dönmez, Grote, \& Brusoni, 2016).

Influenciar o comportamento não apenas da organização, mas de todo o sistema econômico, é uma característica das rotinas na teoria econômica evolucionária (Nelson, 2002). Esse efeito ocorre quando as organizações recombinam suas rotinas operacionais e também quando ocorre a implementação de rotinas de ordem superior, de alto nível, alterando ou substituindo as operacionais. Essas influências das rotinas no sistema econômico são dinamizadas ainda a partir do caráter assimétrico das rotinas de cada unidade mercantil.

Por meio da heterogeneidade das rotinas e de seus mecanismos de seleção, a teoria evolucionária objetiva explicar as mudanças econômicas e as assimetrias organizacionais (Salter \& Mckelvey, 2016). A heterogeneidade é o resultado de diferentes níveis de produção e de pesquisas que geram novas variações de mercado. A assimetria encontra-se no fato de que as rotinas abrangem habilidades e conhecimentos, podendo ser alteradas quando o desempenho desejado é inferior à estratégia organizacional. Assim, as regras de decisão podem ser configuradas a partir destes resultados intencionais. Apresentam, portanto, estabilidade genética e capacidade de mutação endógena.

Em termos de mudanças, as rotinas por meio de sua dinâmica interna podem ser estudadas a partir dos fatores ostensivo e performativo (Safavi \& Omidvar, 2016). O caráter ostensivo é o entendimento das rotinas a partir da percepção dos atores (Wright, 2016). Já o aspecto performativo refere-se às ações específicas desenvolvidas por pessoas específicas em tempos e lugares específicos. A interação de ambos define o sistema generativo das rotinas cujas performances, isto é, aspectos performativos, diferem das representações dos aspectos ostensivos (Feldman \& Pentland, 2003). Por meio do sistema generativo, isto é, do resultado da

Revista Alcance - Eletrônica - vol. 25 - n. 2 - Mai./Ago. 2018 
conjunção dos aspectos ostensivos e performativos, tem-se que as rotinas não são apenas padrões de ação, mas possiveis padrões de ação decorrentes de indivíduos e de contextos organizacionais adaptadas a partir do comportamento do ator em respostas às ações dos outros na realização de certa atividade (Wright, 2016). Essas assimetrias de interpretação aumentam o grau de variabilidade e de divergência em termos de performances das rotinas (Pagell, Klassen, Johnston, Shevchenko \& Sharma, 2015).

Assim, o desempenho da rotina tem como pré-requisito a interpretação e o entendimento da rotina a partir do repertório individual do agente. As performances das rotinas também apresentam como causa os mecanismos de coordenação, isto é, da coordenação relacional dos atores. Essa coordenação pode beneficiar a organização por meio da divisão de conhecimento e de metas, bem como de respeito mútuo.

A teoria evolucionária da economia, assim como os princípios da teoria do crescimento da firma de Penrose (2006), ressalta que o conhecimento, além de assimétrico, encontra-se inserido nas rotinas organizacionais, assemelhando-se aos preceitos da visão da teoria baseada em competência. Trata-se de uma visão cuja aprendizagem é vista como fundamento do crescimento endógeno. Logo, o conhecimento é obtido por meio de processos de cognição e interpretação. Assim, o comportamento da firma por meio das rotinas representa o comportamento e as habilidades dos indivíduos (Miller, Pentland, \& Choi, 2012). A habilidade representa capacidades originadas por indivíduos para realização de determinada tarefa (Vromen, 2006). Os indivíduos nas rotinas, além das habilidades, podem ser estudados a partir de suas relações, por meio da forma como ocorrem.

\subsection{Path dependence e memória organizacional}

As rotinas na teoria econômica evolucionária diferem da teoria clássica que as caracterizam pela concepção prescrita e racional, pois prevê que as oportunidades de mercado são dependentes das rotinas até então desenvolvidas, apresentando caráter de path dependence (Notteboom, Langen, \& Jacobs, 2013). Esse conceito está relacionado com uma série de eventos organizacionais identificados ao longo de determinado tempo, que vão formatando a história da organização em ciclos de interação.

A inovação, assim como as rotinas na economia evolucionária, apresenta o caráter de path dependence, sendo desenvolvido a partir de elementos endógenos, por meio da interação dos fatores como aprendizagem de eventos passados e experiência (Loebel, 2012). Significa que uma organização inovadora terá mais facilidade no futuro de gerar inovação ou de criar oportunidades de rentabilidade.

O caráter de path dependence, nesse sentido, também está relacionado ao conhecimento organizacional em termos tácitos e de complexidade (Bataglia \& Meirelles, 2009). Quanto menor o grau do fator tácito no conhecimento, maior a possibilidade de acesso formal. Já a complexidade refere-se à interpelação entre diversas habilidades, competências e conhecimentos decorrentes.

O path dependence são características organizacionais que persistem ao longo do tempo independente da eficiência atual (Vergne \& Durante, 2011). Isso, conforme os referidos autores, refere-se ao conceito de lock in um resultado do path dependence que abrange o sentido de irreversibilidade. Assim, as decisões organizacionais ao longo do tempo se autorreforçam, tendo influência direta no futuro criando o efeito lock in (Wang, Hedman, \& Tuunainen, 2016).

A formação do path dependence decorre de três fases: pré-formação, formação e lock in. 0 primeiro abrange múltiplas escolhas gerenciais, tecnológicas e de mercado, cujas ações tornam-se mutuamente dependentes do passado e do autorreforço. A fase de formação é dependente de ações prévias, cujas alternativas são irreversíveis ou limitadas. A fase lock in é legitimada pela redução de alternativas e de flexibilidade de ações. Além disso, o path dependence tem relação com a formação das capacidades dinâmicas por meio da seleção do caminho e dos padrões de rotinas acumuladas ao longo da história da organização. Dessa forma, as rotinas também apresentam relação com path dependence, pois sofrem mecanismos de auto reforço.

Estruturado por mecanismo de autorreforço, o path dependence tem como causa a cognição dos sujeitos. Um dos elementos relacionados ao conceito é a ausência de reflexividade organizacional, isto é, a capacidade de os atores observarem de forma sistemática suas ações. (Thrane, Blaabjerg, \& Moller, 2010). Para Nelson e Winter, (1982) as limitações cognitivas fazem com que as organizações tenham uma interpretação insuficiente do mercado. Relevante destacar que as interpretações dos sujeitos, a partir de suas cognições, são tomadas a partir da história da organização. Assim, as organizações retêm algumas interpretações que acabam por compor a cultura e a identidade organizacional. Esses elementos fundamentam o path dependence (Thrane, Blaabjerg, \& 
Moller, 2010). Assim, a cognição é um dos elementos que modela a estratégia das indústrias (Spender, 1989). 0 conceito de path dependence também é influenciado pela diversidade de cognição.

Em termos de memória organizacional, por sua vez, é preciso antes contextualizar que as habilidades individuais são análogas às rotinas e que sua compreensão depende da identificação das habilidades individuais dos atores (Nelson \& Winter, 2005). As habilidades dizem respeito ao comportamento regular e eficiente no desempenho de uma escolha deliberada. Assim os indivíduos, por meio do conjunto de habilidades, representam a base das rotinas que são operacionalizadas por meio de múltiplos padrões de interações entre estes (Vromem, 2006). 0 conjunto de habilidades e rotinas, que é desenvolvido pelos indivíduos, é definido como o repertório. Assim, ao receber uma mensagem e enviar aos demais membros, o indivíduo utiliza esta informação para executar uma determinada rotina a partir de seu próprio repertório.

Existe, portanto, um fluxo circular de repertórios individuais que operacionalizam a rotina, logo, afirma-se que a memória organizacional é resultante das rotinas desenvolvidas e que em uma análise mais profunda é composta pelo repertório individual. A memória organizacional, portanto, não representa apenas a explicitação de documentos ou planos formais, mas apresenta caráter subjetivo de conhecimento tácito complexo de ser articulado.

Logo, a aprendizagem da organização envolve a alteração de modelos mentais envolvendo construção e reconstrução a partir acertos e erros (Hodgson, 1998). Afirma-se, dessa forma, que a aprendizagem inicia no indivíduo a partir das diferenças entre os resultados atuais e esperados. A partir destes elementos é que os modelos ou estruturas mentais são alterados. Em termos organizacionais, na sequência, infere-se que aprendizagem organizacional, decorrente de reflexão, compõe a memória organizacional. A memória organizacional compreende a procedural, declarativa e transitiva. A primeira refere-se ao conhecimento tácito do indivíduo, ao know how que se explicita a partir do desempenho em uma determinada atividade sendo menos explícita. A memória organizacional procedural também representa o conhecimento coletivo tácito da organização que gera vantagem competitiva (Ebbers \& Wijnberg, 2009). Existe, ainda, a relação entre memória organizacional com a inovação especialmente a que se refere ao desenvolvimento de produtos (Chang \& Cho, 2008). Já a memória declarativa representa o know what, incluindo descrições, proposições e imagens, contudo, podendo ser desenvolvida por meio de interpretações de situações identificando ações adequadas a ação. Ambas as memórias declarativas e procedurais auxiliam para o desempenho da performance das rotinas organizacionais (Miller; Pentland; Choi, 2012).

As habilidades individuais referem-se ao know how e às sequências de ação que compõem uma rotina como kow what, abrangendo o conhecimento declarativo. A memória declarativa auxilia na solução de restrições das rotinas, indicando sequências de ação a partir do passado. Já a memória transativa representa o know how, isto é, o acesso que os indivíduos fazem em termos de conhecimento externo para solução de restrições que não conseguem desenvolver individualmente. A interação faz com que ocorra a memória transativa por meio da divisão de conhecimentos e de comunicação. Assim, a rotina organizacional decorre da memória transativa, pois serve de ligação entre habilidades individuais e capacidades coletivas (Miller, Choi, \& Pentland, 2014). Em termos de rotinas, a interação humana ou não humana, como artefatos, representa o compartilhamento de entendimentos, ocasionando padrões de ação repetitivos (Bapuji, Hora, \& Saeed, 2012). Artefatos, contratos ou softwares são considerados intermediários que conectam atores para execução da performance planejada.

As rotinas sendo representadas como as coisas são desenvolvidas nas organizações e apresentam sentido sobre como as organizações se renovam por meio de conhecimento tácito e da memória organizacional. A memória apresenta relação com a visão baseada em recursos e está atrelada com o estoque de conhecimento, a qual pode ser convertida em performance e representa uma série de eventos passados, metas e comportamentos (Ebbers \& Wijnberg, 2009). Dessa forma, a cultura organizacional abrange normas, valores e rituais; a estrutura compreende estrutura de poder, mecanismos de comunicação, técnicas e métodos, sistemas e procedimentos; os sistemas, por sua vez, correspondem a indicadores de performance, sistema de controle de orçamento, de pagamento e financeiro; os procedimentos referem-se às rotinas, processo de criação de produtos, regras procedimentos de operações (Bent, Paauwe, \& Willians, 1999).

A memória organizacional manifesta-se em três bases: cognitiva, experiência organizacional e artefatos físicos (Chang \& Cho, 2008). A primeira abrange modelos, valores, normas e estruturas de referência. A segunda refere-se a elementos comportamentais, como rotinas formais, informais e procedimentos. Os artefatos físicos, por sua vez, dizem respeito à estrutura organizacional e layout físico. Assim, a memória organizacional representa o conhecimento coletivo que é obtido por experiência e estocada em várias partes da organização, sendo difícil

Revista Alcance - Eletrônica - vol. 25 - n. 2 - Mai./Ago. 2018 
de ser mudada, pois é acumulada e reforçada ao longo do tempo na organização. A memória organizacional é o resultado de padrões históricos de informações que são resgatados para a tomada de decisão (Fiedler \& Welpe, 2010). A memória é desenvolvida a partir da estrutura da organização, do grau de interação entre os agentes e também de seus artefatos. Conforme os autores, a estrutura da organização no que tange à especialização e à padronização influencia a memória organizacional.

\subsection{0 individualismo metodológico e as rotinas}

A explicação dos componentes dos átomos por meio de Demócrito e Leucipo originou o individualismo metodológico (Chafim \& Krivochein, 2011), influenciando na sequência Thomas Hobbes e John Locke para entender a sociedade por meio dos indivíduos. O individualismo metodológico surge por meio de Adam Smith, em 1776, com sua obra da Riqueza das Nações, por meio do liberalismo clássico, defendendo a independência e a autonomia, fazendo com que o sujeito seja um expoente da totalidade (Arrow, 1994; Hunt \& Sherman, 2004). Joseph Schumpeter, em 1908, foi um dos pioneiros a fundamentar o individualismo metodológico. $\mathrm{Na}$ ordem cronológica, em 1934, John Ricks e Fritz Machlup, em 1937, também mencionaram, em seus trabalhos, o termo individualismo metodológico, seguidos por Ludwig Von Mises, em 1949; Frederick Hayek, em 1942; e Karl Popper, em 1945 (Hodgson, 2007). $O$ termo iniciou na economia como um conceito convergente, posteriormente adotando caráter polissêmico, sendo estudado em áreas como sociologia e antropologia.

O individualismo metodológico foi proposto pelos economistas austríacos: Carl Menger (1840-1921), Eugen Von Bohm Bawerk (1851-1914), Friedrich Von Wieser (1851-1926) e Hayek (Papanikos, 1998). Hayek defende o subjetivismo, isto é, o individualismo metodológico para compreensão dos fenômenos da ciência social, tendo 0 objetivo de compreender a sociedade a partir das idiossincrasias dos indivíduos, por meio de suas informações, contrariando o pressuposto de que toda ação social é uma tentativa de modificar a sociedade (Papanikos, 1998). Defende o subjetivismo nas ciências sociais, pois as visões e as percepções, diferentemente das ciências físicas naturais, são relevantes na investigação do processo (Papanikos, 1998).

Ademais, acerca do indivíduo, Schumpeter (1968) afirma que as ações dos sujeitos decorrem de vários motivos, não devendo considerá-lo apenas pela lógica. O individualismo metodológico, na economia, justifica-se por ser o indivíduo detentor da riqueza individual (Schumpeter, 1954). Dessa forma, o ciclo da demanda, da produção e do pagamento decorre do desejo do indivíduo. Reitera também que o valor social se desenvolve a partir da ação agregadora dos interesses dos indivíduos e da riqueza individual. Schumpeter (1947), acerca do individualismo metodológico, resgata o empreendedor como 0 agente responsável pela promoção das respostas criadoras que transformam a dinâmica capitalista. A importância do indivíduo na economia é legitimada ainda por Perroux (1967), que assevera que o crescimento econômico tem origem no psiquismo por meio das personalidades dos atores, cujo economicismo é doutrinado apenas por forças anônimas. Para o autor, o cálculo racional dos efeitos não deve suprimir os humanos, devendo reconhecer seu movimento e transformação. Assim, o individualismo metodológico é a interação dos indivíduos em suas crenças e atitudes para compreensão do fenômeno econômico (Arrow, 1994).

O individualismo metodológico define que os indivíduos são os formadores da totalidade e que esta complexidade é o resultado singular das crenças e das circunstâncias destes (Haguette, 2003). Contudo, a complexidade reside na antinomia estrutura-holismo e ação-indivíduo. Uma das teorias que defende as análises de origem micro com estrutura é a teoria da ação estrutural-funcionalista de Talcott Parsons (Haguette, 2003). Diferentemente, a teoria dialética de Karl Marx (1974) é considerada como estruturalista, isto é, holista com elementos de desestruturação. $O$ individualismo metodológico pode ser estudado ainda a partir de Marx (1974). Em sua obra O Capital, Karl Marx trata-se da coletividade em termos de firmas individuais sem, contudo, acessar o indivíduo. Isso abriu espaço para os marxistas analíticos, pela carência de conhecimento em nível de micro fundamentos. Os marxistas analíticos ou marxistas subjetivos ou de escolha racional, não reducionistas, estudam a dinâmica da Marx a partir de microanálises (Chafim \& Krivochein, 2011; Veneziani, 2012). Em decorrência da teoria marxiana tratar da dialética, é necessário que esta seja concebida por meio do individualismo metodológico, estudando o indivíduo como transformador da história.

A complexidade das discussões acerca do individualismo metodológico é originada ora pela defesa daqueles que afirmam que os processos sociais somente podem ser compreendidos a partir de indivíduos e de suas relações e, por outro lado, por aqueles que defendem o holismo radical, afirmando que as coletividades somente podem ser entendidas pelos indivíduos (Haguette, 2003). Conforme Udehn (2001), ao defender 0 individualismo ontológico, as entidades sociais são formadas por sujeitos e essa totalidade não se desenvolve 
independente dos indivíduos. Essa afirmativa assemelha-se ao atomismo, em que as propriedades se reduzem à individualidade (Chafim \& Krivochein, 2011). A contradição reside, portanto, no reducionismo e no holismo. Uma fonte intermediária desta compreensão é defendida pelos marxistas analíticos, como Erik Olin Wright, que, embora defenda o holismo da estrutura, não concorda com o reducionismo das microanálises.

O entendimento de Carl Menger, contudo, trata o individualismo metodológico a partir do método genético causal, cujos eventos estão unidos por meio de causalidades (Feijó, 2000). A totalidade social é entendida como interação entre suas partes. $O$ teórico Von Mises, por sua vez, renega a regularidade da totalidade social. Assevera que, a partir das ações individuais, é que se obtêm regularidades (Feijó, 2000). Segundo o autor, o entendimento dos cursos de ação subjetivamente definidos pelos indivíduos somente é possível por meio da história e da teoria. A primeira contribui para a compreensão da realidade (Feijó, 2000). Já a teoria é o conjunto de preceitos categóricos que se conectam logicamente com outros conceitos. Tanto Mises quanto Hayek acreditam que a totalidade social pode ser explicada a partir da subjetividade dos agentes.

Segundo de Hosdgson (2007), o fenômeno social referente ao individualismo metodológico deve ser entendido a partir do indivíduo e de suas relações cuja organização cria as contingências necessárias entre atores e estrutura. Quando concebidos a partir da posição social, os indivíduos representam não apenas suas qualidades ou poderes, mas também características referentes à posição em que ocupa (Hosdgson, 2007). Portanto 0 fenômeno social deve ser analisado a partir de indivíduo e estrutura social. A estrutura social condiz com padrões individuais, mas também com grupos que interagem e que originam propriedades emergentes destas interações. Portanto a compreensão destes fenômenos sociais é viável a partir da interação entre os agentes (Davis, 2003).

Entendimento semelhante é compartilhado pela microeconomia sistêmica ou evolucionária, em que as partes estão interligadas pela estrutura social formada por ações e interações sociais (Prados, 2006). Existe uma conjunção de elementos e relações heterogêneas sem, contudo, isolar sujeito e estrutura. Assim, a evolução das rotinas deve ser estudada a partir das relações endógenas que a compõem ao longo de uma trajetória (Chen, Pan, \& Ouyang, 2014).

As ações organizacionais são desenvolvidas por indivíduos, representando uma criação intencional (Hodgson, 1998). Isso resulta de que até os fatores de produção não apresentam passividade, pois os indivíduos apresentam possibilidades de escolha, o que legitima o grau de incerteza (Simon, 1951). A incerteza está associada à ação humana na economia. $O$ indivíduo possui habilidades tácitas e idiossincráticas difíceis de serem mensuradas. Para compreender o comportamento do indivíduo na organização, é necessário que sejam observadas as suas inter-relações (Vromen, 2006).

\subsection{Investigação de inferências entre rotina, individualismo metodológico, path dependence e memória organizacional}

Após revisão bibliográfica, estrutura-se na Figura 10 quadro conceitual que antecede o framework para 0 estudo das rotinas organizacionais. 


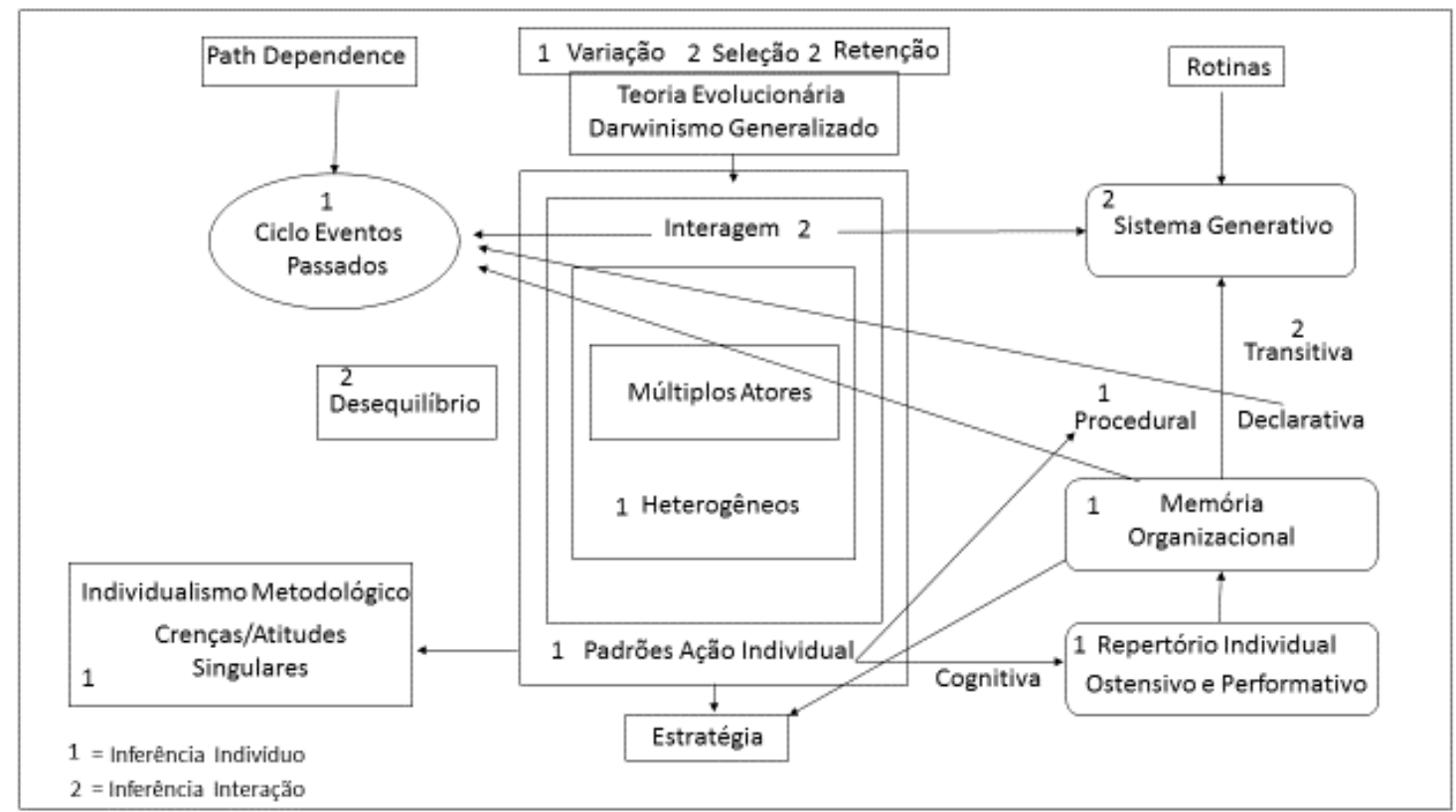

Figura 1: Inferências entre path dependence, memória organizacional, individualismo metodológico e economia evolucionária Fonte: Elaborada pelos autores (2018).

A teoria evolucionária a partir do darwinismo generalizado parte do pressuposto de que múltiplos atores heterogêneos interagem na organização em um ambiente em desequilíbrio. Assim, tem-se os padrões de ação individual. As inferências, representadas pelo número 1, podem ser identificadas a partir dos padrões de ação individual (1), que apresenta similaridade com atores heterogêneos (1).

Dentro da teoria evolucionária, identificou-se que o elemento variação também está relacionado com 0 potencial de variação humana, conforme conceitua Schumpeter (1968). Os padrões de ação individual (1) também apresentam semelhança com os pressupostos do individualismo metodológico (1), cujos agentes são dotados de crenças e atitudes singulares.

No estudo das rotinas, também se identificou correlação entre repertório individual (1) e memória organizacional procedural (1), pois ela está inserida nas rotinas a partir da subjetividade do indivíduo. Também se resgatou inferência entre memória organizacional (1), que reside no agente com os ciclos de eventos passados (1) que correspondem ao path dependence.

A teoria possibilita inferir ainda, conforme se demonstra na Figura 1, que os padrões de ação individual (1) estão relacionados ao repertório individual (1), que no estudo das rotinas se refere ao aspecto ostensivo e performativo. 0 primeiro se refere ao entendimento subjetivo do ator quanto à rotina e o segundo à performance desta. Ambos, quando interagem (2) a partir dos sujeitos, formam o sistema generativo das rotinas, estabelecendo o caráter de inferência (2), que corresponde à mudança ou à quebra do núcleo estacionário da organização, por meio da interação (2) entre os agentes, gerando desequilíbrio (2) na organização.

A inferência interação (2) também apresenta correlação com o conceito de memória transitiva, que é obtida tendo como condição a interação do sujeito e não apenas com seu repertório individual. A interação (2) também pode ser adotada para gerar mudanças e desequilíbrios a partir dos pressupostos de seleção e retenção. Identificadas as relações de inferências (1) a partir do agente e da interação (2) em prol da mudança, propõe-se framework para estudo das rotinas organizacionais a partir do individualismo metodológico interacionista, do path dependence e da memória organizacional.

\subsection{Framework para estudo das rotinas organizacionais}

$\mathrm{Na}$ Figura 2, apresenta-se o framework conceitual para o estudo das rotinas organizacionais a partir dos aspectos ostensivo e performativo, tomando por base os elementos de inferência individual do individualismo metodológico (1) e da inferência interação (2) representada pelo individualismo metodológico interacionista (2). 


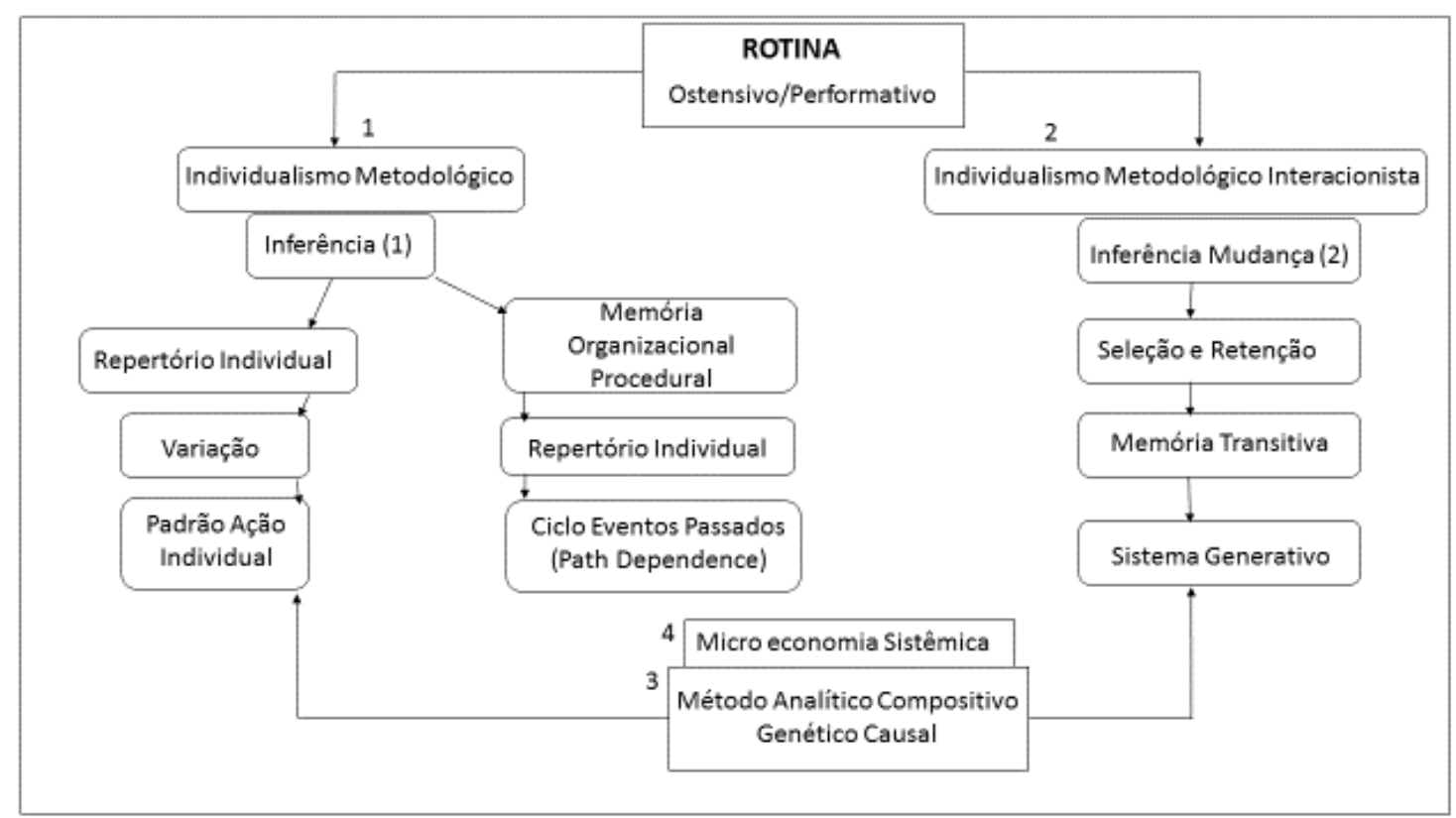

Figura 2: Framework para estudo das rotinas evolucionárias Fonte: Elaborada pelos autores (2018).

Conforme o framework na Figura 2, entende-se que a rotina deve ser estudada a partir dos aspectos ostensivo e performativo (Feldman \& Pentland, 2003). A rotina deve ser estudada ainda a partir de quatro princípios lógicos: individualismo metodológico (1), individualismo metodológico interacionista (2), método analítico compositivo, genético causal (3) e microeconomia sistêmica (4). 0 primeiro e o segundo princípio justificam-se como pilares do modelo, dado que a economia evolucionária abrange o repertório individual e a interação (Nelson \& Winter, 2005). Já o método analítico compositivo e genético causal (3) contribui por estudar o todo, isto é, a organização a partir de suas partes, no caso, os agentes, estabelecendo relações de causa e efeito (Feijó, 2000). Já o pilar microeconomia sistêmica se justifica, pois ao interagir o indivíduo com a estrutura, novos padrões emergentes estratégicos surgem. Além disso, ocorre uma conjunção entre a substância, isto é, a estrutura, o todo e os padrões ou as formas de interação, típico das auto-organizações (Capra, 2006)

Ao propor o estudo da rotina a partir do individualismo metodológico (1), reconhece-se a relevância do agente na teoria econômica evolucionária e também no construto. Entende-se que 0 agente é a fonte de todo 0 potencial estratégico e de mudança que se encontra na operacionalização da rotina. Assim o repertório individual, isto é, habilidades, conhecimentos e atitudes, pode ser utilizado para caracterização do ambiente competitivo na qual a organização está inserida. Ao explicitar o repertório individual, a partir do princípio evolucionário variação, tem-se a execução do potencial de variação humana. Por meio do indivíduo, caracterizam-se, na concepção deste, os elementos estratégicos da organização como: erros, tendências de mercado, aprendizagem por meio de solução de problemas organizacionais.

Pode-se ainda, por meio do repertório individual e da variação evolucionária, por meio do individualismo metodológico (1), aumentar a capacidade de absorção e adaptação da organização, caracterizando propriedades emergentes que decorrem dos agentes econômicos, como concorrentes, fornecedores (Bataglia \& Meirelles, 2009). Ao unir repertório individual e variação por meio do individualismo metodológico, isto é, reconhecendo que o indivíduo influencia a estrutura, ocorre a maximização do padrão de ação individual.

0 individualismo metodológico (1), que resgata a relevância do indivíduo, também deve ser estudado a partir da memória organizacional procedural do agente, pois este representa o repertório individual. Assim, ao utilizar o repertório individual para a compreensão de eventos passados do path dependence, é possível fazer com que a organização aprenda com elementos em termos de erros e acertos, dada a reflexividade organizacional (Thrane, Blaabjerg, \& Moller, 2010). A compreensão do passado por meio do versthen pode fazer com que a gestão projete um futuro estratégico, reconhecendo que a organização é o resultado do passado e do presente (Feijó, 2000). Ao se reconhecer os eventos do passado, ocorre o tempo dinâmico, cuja aprendizagem torna-se intencional por meio de ajustes de processos. Por meio disso, pode-se evitar o conceito de lock in ou de irreversibilidade, tendo em vista que as escolhas gerenciais podem ser revistas corrigindo mecanismos de

Revista Alcance - Eletrônica - vol. 25 - n. 2 - Mai./Ago. 2018 
autorreforço do passado (Vergne \& Durand, 2011).

Contudo, ao estudar as rotinas por meio do individualismo metodológico (1), com vistas a obter a capacidade de mudanças das rotinas por meio dos agentes promovendo o aspecto generativo, é mister que esta seja desenvolvida a partir do individualismo metodológico interacionista (2) por meio da inferência mudança (2). Este apresenta um potencial de mudança para a rotina organizacional a partir de múltiplos entendimentos entre os atores. Parte-se, portanto, do agente para a estrutura, para o holismo. Esse princípio lógico da interação evita 0 individualismo metodológico atomista ou reducionista. Ao interagir com o todo, 0 agente potencializa sua capacidade de aprendizagem e também de alavancagem de mudança da rotina. A memória transativa se desenvolve por meio das interações entre os indivíduos, seja endogenamente na organização ou exogenamente com outros agentes por meio da divisão do conhecimento.

A memória transativa é o elo entre o repertório individual e o repertório coletivo, isto é a rotina. A inferência mudança (2), ao utilizar os princípios do individualismo metodológico interacionista (2) nos pilares seleção e retenção, contribui para a memória transitiva, pois por meio destes pilares todo o potencial de variação identificado no indivíduo pode ser absorvido através da coletividade em termos de elementos do ambiente competitivo. Isso contribuirá para o sistema generativo das rotinas. A inferência mudança (2), a partir do princípio da interação, promoverá que a organização evolua estrategicamente, pois ocorre a mudança do equilíbrio estacionário da rotina. Conforme Senge (1990), quando menos determinado o sistema, mais complementar. Além disso, as rotinas apresentam capacidade de transformação endógena (Nelson, 2002). Requerem, contudo, coordenação relacional entre as partes, o que justifica os pilares basilares do framework, individualismo metodológico (1) e individualismo metodológico interacionista (2).

\section{CONSIDERAÇÕES FINAIS}

O trabalho, em um primeiro momento, contribui para o estudo das rotinas por meio da apresentação dos elementos de inferência da economia evolucionária relacionadas ao individualismo metodológico como os padrões de ação individual e repertório individual, atores heterogêneos, memória organizacional procedural e ciclo de eventos passados. Também foram explicitadas inferências de interação em prol da mudança entre os conceitos memória transativa, sistema generativo e desequilíbrios.

O trabalho também contribui para o estudo das rotinas organizacionais, pois as inferências de similaridade e de mudança foram inseridas num framework conceitual a partir da conjunção de quatro princípios: individualismo metodológico, individualismo metodológico interacionista, método analítico compositivo e genético causal e microeconomia sistêmica. No individualismo metodológico, defende-se que o repertório individual contribui para a organização a partir do momento em que se insere este no conceito de variação, potencializando o padrão de ação individual por meio da aprendizagem. Já as conjunções da memória organizacional procedural com ciclos de evento do passado contribuem para a organização para evitar o conceito de irreversibilidade por meio de ajustes de ações gerenciais e elementos de autorreforço, ampliando a gama de oportunidades futuras por meio do verstehen.

Esses elementos, relacionados ao repertório individual e à memória legitimada pelo individualismo metodológico, devem ser inseridos na lógica da mudança coletiva por meio do individualismo metodológico interacionista. Tem-se neste segundo bloco os atores participando dos elementos de seleção e retenção por meio da memória transativa, isto é, dividindo conhecimentos acerca dos elementos elencados na variação de cada um deles. Isso contribui para o sistema generativo das rotinas organizacionais.

Assim, conclui-se que o trabalho contribui para o estudo das rotinas organizacionais por meio da identificação de que o construto seja pesquisado a partir de uma coerência lógica, isto é, a partir do indivíduo, sem, contudo, renegar o todo, isto é, o holismo. O framework, sendo assim, atesta que as rotinas devem ser estudadas, portanto, a partir de uma lógica de interação, partindo do indivíduo para a organização, valorizando 0 potencial de variação humana e as propriedades emergentes geradas na evolução com o ambiente, sendo necessário o mapeamento do padrão ou forma destas interações, pois a estrutura organizacional representa a absorção destes padrões.

Como limitações deste estudo, observa-se que os conceitos de gestão sistêmica e auto-organização no contexto da economia evolucionária devem ser aprofundados, isso ampliaria a profundidade e o alcance das análises geradoras do modelo teórico proposto. Como indicações para estudos futuros, indica-se desenvolver estudos empíricos que testem o framework desenvolvido teoricamente. 


\section{REFERÊNCIAS}

Alchian, A. A. (1950). Uncertainty, Evolution, and Economic Theory. The Journal of Political Economy, 58(3), 211221. The University of Chicago Press.

Arrow, J. K. (1994). Methodological individualism and social knowledge. The American Economic Review, 84, 1-9.

Bapuji, H., Hora, M., \& Saeed, M. A. (2012). Intentions, Intermediaries, and Interaction: Examining the Emergence of Routines. Journal of Management Studies, 49(8), 1586-1607.

Bataglia, W., \& Meirelles, S, D. (2009). Population ecology and evolutionary economics: toward na integrative model. Management Research, 7(2), 87-101, Spring.

Becker, M. (1982). The concept of routines twenty years after Nelson and Winter. A Review of the literature. Danish Research Unit for industrial Dynimics. Druid Working Paper, 03-06.

Bent, V. J., Paauwe, J., \& Willians, R. (1999). Organizational learning: na exploration of Organizational memory and its role in organizational change processes. Journal of Organizational Change Management, 12(5), 377 404.

Capra, F. (2006). A teia da vida: uma nova compreensão científica dos sistemas vivos. São Paulo: Cultrix.

Chafim, V. F., \& Krivochein, C. (2011). Contribuições a crítica do individualismo metodológico na economia. Revista Nexos, 5(9).

Chang, R. D., \& Cho, H. (2008). Organizational memory influences new product success. Journal of Business Research, 61, 13-23.

Chen, E. J., Pan, L. S., \& Ouyang, H. T. (2014). Routine reconfiguration in traditional companies' e-commerce strategy implementation: A trajectory perspective. Information and Management, 51, 270-282.

Cyert, R. M., \& March, J.G. (1992). A behavioral theory of the firm (2a ed.). Malden, MA: Blackwell.

Davis, J. B. (2003). The theory of the individual in economics: identity and value. London na New Your: Routledge.

Dönmez, D., \& Grote, G. (2016). Brusoni. Routine interdependencies as a source of stability and flexibility. A study of agile software development teams. Information and Organization, 26, 63-83.

Ebbers, J. J., \& Wijnberg, M. N. (2009). Organizational memory: From Expectations Memory to Procedural Memory. British Journal of Management, 20, 478-490.

Evans, K. S. (2011). Connecting adaptation and strategy: the role of evolutionary theory in scenario planning. Futures. 43, 460-468.

Feijó, R. (2000). Economia e filosofia na escola austríaca. São Paulo: Nobel.

Feldman, M. S., \& Pentland, B. T. (2003). Reconceptualizing organizational routines as a source of flexibility and change, Administrative Science Quarterly, 48, 94-118.

Fiedler, M., \& Welpe, I. (2010). How do organizations remember? The influence of organizational structure on organizational memory. Organization Studies, 31(4), 381-407.

Foucault, M. (2008). Arqueologia do saber. Rio de Janeiro: Forense Universitária.

Friedman, M. (1953). The methodology of positive economics. In Essays in Positive Economics. Chicago: Chicago University Press.

Hunt, K. E., \& Sherman, J. H. (2004). História do pensamento econômico (21a ed.). Petrópolis, Rio de Janeiro: Editora Vozes.

Laakkonen, A., \& Kansikas, J. (2011). Evolutionary selection and variation, in Family businesses. Management Research Review, 34(9), 980-995.

Loebel, E. (2012). Organizational routine and performance: theoretical and methodological considerations from an evolutionary perspective of the firm. Anais do XXXVI Encontro da ANPAD. Rio de Janeiro.

Haguette, F. M. T. (2003). Metodologia qualitativa na sociologia. Petrópolis: Editora Vozes.

Hodgson, M, G. (1998). Evoltuionary and competence -based theories of the firm. Journal of Economic Studies, 25(1), 25-56.

Hodgson, M. G., \& Knudsen, T. (2004). The firm as na interactor: firms as vehicles for habits and routines. Journal of Evolutionary Economics, 14, 281-307.

Hodgson, M. G. (2007). Meaning of methological individualism. Journal of Economic Methodology, 14(2), 211-222.

Revista Alcance - Eletrônica - vol. 25 - n. 2 - Mai./Ago. 2018 
Nelson, R., \& Winter, G. S. (1982). Uma teoria evolucionária da mudança econômica. São Paulo: Unicamp.

An evolutionary theory of economic change. Belknap Press of Harvard University Press: Cambridge, MA.

Nelson, R. (2002). Bringing institutions into evolutionary growth theory. Journal of Evolutionary Economics, SpringVerlag, 12, 17-28.

Notteboom, T., Langen, P., \& Jacobs, W. (2013). Institutional plasticity and path dependence in seaports: interactions between institutions, port governance reforms and port authority routines. Journal of Transport Geography, 27, 26-35.

Marx, K. (1974). O capital. Rio de Janeiro: Civilização Brasileira.

Miller, D. K., Pentland, T. B., \& Choi, S. (2012). Dynamics of Performing and Remembering Organizational Routines. Journal of Management Studies, 49(8), 1536-1558.

Miller, D. K., Choi, S., \& Pentland, T. B. (2014). The role of transactive memory in the formation of organizational routines. Strategic Organization, 12(2), 109-133.

Papanikos, T. G. (1998). Methodological individualism economic behaviour and economic policy. International Journal of Social Economics, 25(9), 1342-1352.

Pagell, M., Klassen, R., Johnston, D., Shevchenko, A., \& Sharma, S. (2015). Are safety and operational effectiveness contradictory requirements: the roles of routines and relational coordination. Journal of Operations Management, 36, 1-14.

Penrose, E. (2006). A teoria do crescimento da firma. Campinas, São Paulo: Unicamp.

Pentland, T. B., Feldman, S. M., Becker, C. M., \& Liu, P. (2012) Dynamics of Organizational Routines: A Generative Model. Journal of Management Studies, 49(8), 1484-1508.

Perroux, F. (1967). A economia do século XX. Editora Lisboa.

Prados, F. E. (2006). Microeconomia reducionista e microeconomia sistêmica. Nova Economia Belo Horizonte, 16(2), 303-322.

Possas, L. M. (2008). Economia evolucionária neo-schumpeteriana: elementos para uma integração micromacrodinâmica.

Safavi, M., \& Omidvar, O. (2016). Resist or Comply: The Power Dynamics of Organizational Routines during Mergers. British Journal of Management, 27, 550-566.

Salter, J. A.; Mckelvey, M. (2016). Evolutionary analysis of innovation and entrepreneurship; Sidney G. Winterrecipient of th 2015 Global Award for Entrepreneurship Research. Small Bus.Econ, 47, 1-14.

Schumbert, C. (2014). "Generalized darwinismo" and the quest for na evolutionary theory of policy-making. J. Evol.Econ, 24, 479-513.

Schumpeter, J. A. (1954). History of economics. Oxford University Press. . (1947). La respuesta creadora en la historia económica. Ensayos. Barcelona: Oikos-Tau. (Originalmente publicado em 1947).

. (1968). Fundamentos do pensamento econômico. Biblioteca de ciências sociais. Rio de Janeiro.

Senge, P. M. (1990). A quinta disciplina: arte, teoria e prática da organização de aprendizagem. São Paulo: Best Seller.

Spender, J.C. (1989). Industry Recipes. Basil Blackwell Ltd., Oxford.

Smith, A., \& Ricardo, D. (1974). Investigação sobre a natureza e as causas da riqueza das nações. São Paulo: Editora Abril S/A.

Thrane, S., Blaabjerg, S., \& Moller, H. R. (2010). Innovative path dependence: making sense of product and servisse innovation in path dependente innovation processes. Research Policy, 39, 932-944.

Udehn, L. (2001). Methodological individualism: background, history and meaning. London: Routledge.

Vaisman, E. (2006). Marx e a filosofia: elementos para a discussão ainda necessária. Nova Economia-Belo Horizonte, 16(2), 327-341.

Veneziani, R. (2012). Analytical marxism. Journal of Economics Surveys, 26(4), 649-673.

Vergne, P. J., \& Durand, R. (2011). The Path of Most Persistence: An Evolutionary Perspective on Path Dependence and Dynamic Capabilities. Organization Studies, 32(3), 365-382. 
Vromen, J. J. (2006). Routines, genes and program-based behavior. J Evol Econ, 16, 5543-560.

Wang, J., Hedman, J., \& Tuunainen, K. V. (2016). Path Creation, Path Dependence and Breaking Away from the Path: Re-Examining the Case of Nokia. Journal of Theoretical and Applied Electronic Commerce Research, 11(2), 16-27.

Winter, S. G. (1964). Economic Natural selection and the tehory of the firm. Yale Economic Essays, 4, 225-272.

Wright, A. (2016). Organizational routines as embodied performatives: A communication as constitutive of organization perspective. Organization, 23, 2, 147-162. 